\title{
Exhibition, Conservation, and Documentation at the National Museum (Nay Pyi Taw)
}

\author{
Aye Aye Thinn
}

\begin{abstract}
The National Museum (Nay Pyi Taw) is under construction and the first phase was opened on 15 July 2015. The exhibition policy is: to present national prestige and integrity; to reveal national cultural heritage to show the soft power and ability of the nation; to build a museum fitting the nation's prestige and grade; and to construct the museum as a good, modern, and attractive one with the right preservation techniques and of a high standard. A total of 12,975 objects have been collected, some excavated from ancient sites and others provided by donation, exchange, or given as awards. Each object arriving at the museum is systematically documented and is being conserved with simple chemicals and ordinary equipment. There is a need for modern techniques of conservation, documentation, and exhibition.
\end{abstract}

\section{Introduction}

The Ministry of Culture has four pillars: Ministers' Office, Department of Fine Arts, Department of Historical Research, and Department of Archaeology and National Museum.

The National Museum (Nay Pyi Taw) is one of the sections under the Department of Archaeology and National Museum. Before 2010, there was only one national museum in Myanmar. The National Museum (Nay Pyi Taw) is situated on 35.19 acre plot on Yazathingaha Road, near lotus Kumudra round about in Uttara Thiri township in Nay Pyi Taw (Figs. 1 and 2). Ground breaking for construction of the museum was started on 3 June 2010. In fact, the National Museum (Nay Pyi Taw) consists of eight buildings but only five buildings have currently been constructed (Fig. 3) and the total floor area is 298,865 square feet. Building (A) has a reception hall, theater, VIP rooms, and reception counter. Building (B) consists of six rooms,

\footnotetext{
A.A. Thinn $(\bowtie)$

National Museum (Nay Pyi Taw), Yazathingaha road, Uttara Thiri township, Nay Pyi Taw, Myanmar

e-mail: aathinn.thinn6@gmail.com 


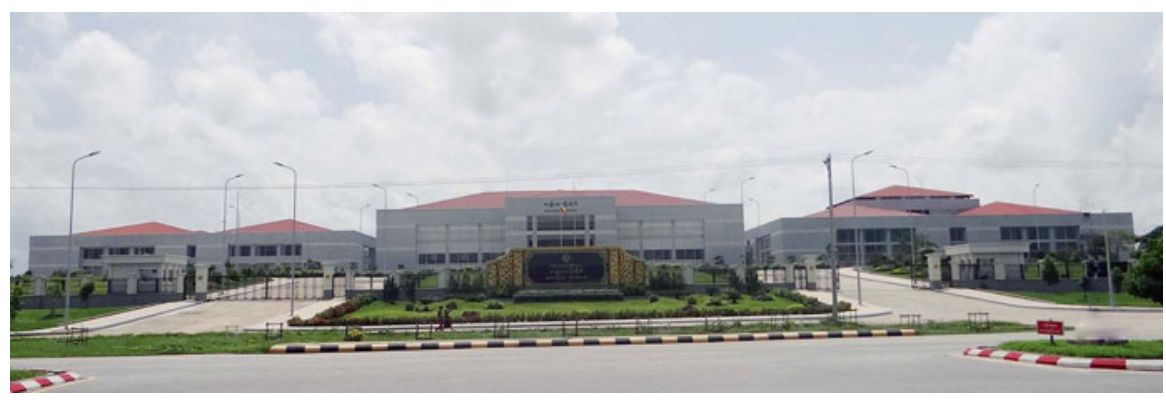

Fig. 1 National museum (Nay Pyi Taw)

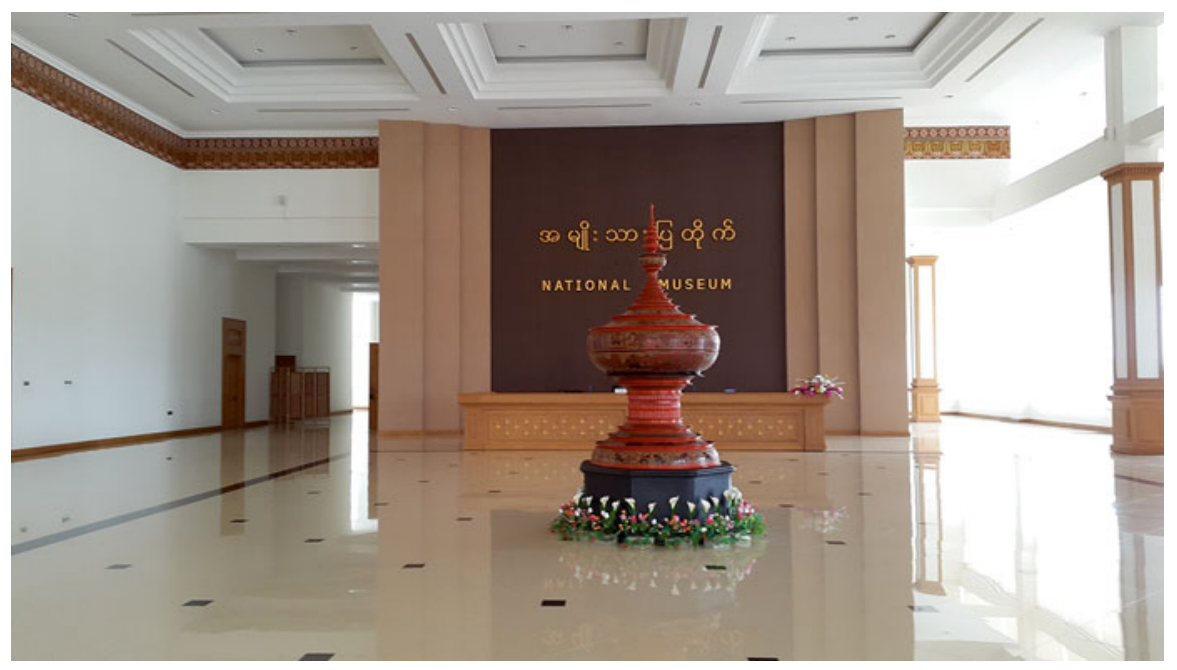

Fig. 2 Reception hall of the National Museum (Nay Pyi Taw)

Building (C) has five rooms, Building (D) has four rooms, and Building (E) has four rooms. Altogether, there are $19(100 \mathrm{ft} \times 100 \mathrm{ft})$ rooms in the National Museum (Nay Pyi Taw).

Our exhibition policy is as follows:

1. To present national prestige and integrity

2. To reveal our national cultural heritage, which is rich and of a high standard

3. To show the soft power and ability of our nation

4. To build a museum fitting our nation's prestige and grade

5. To construct the museum as a good, modern, and attractive one with the right preservation techniques and of a high standard

According to the policy, the National Museum (Nay Pyi Taw) has been constructed and there will be 17 exhibition rooms as follows:

1. Primate and Fossils exhibition room

2. Prehistoric Period exhibition room 


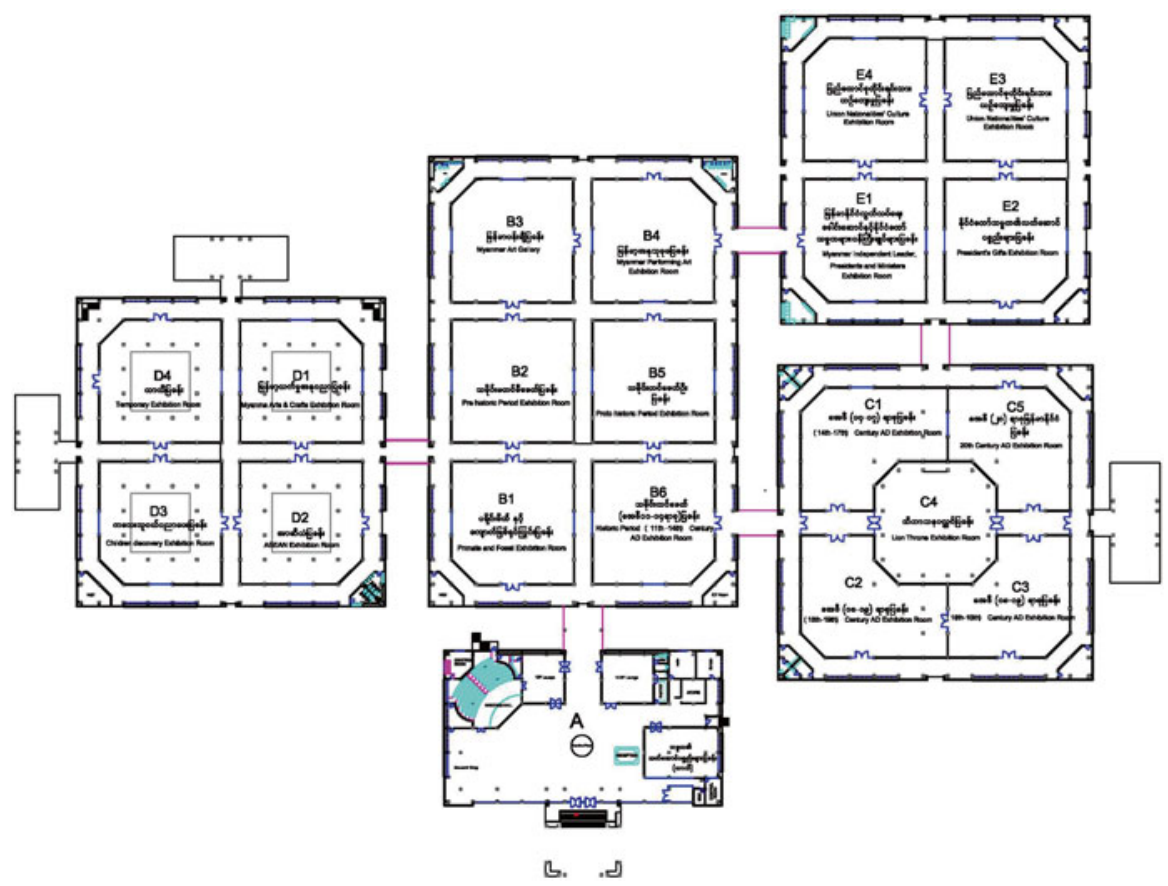

Fig. 3 Current condition of National Museum (Nay Pyi Taw): five buildings have been constructed

3. Protohistoric Period (second century BC to tenth century AD) exhibition room

4. Historic Period of eleventh to thirteenth century AD exhibition room

5. Historic Period of fourteenth to seventeenth century AD exhibition room

6. Historic Period of eighteenth to nineteenth century AD exhibition room

7. Lion Throne exhibition room

8. Colonial period (1885-1948) and the Period after Gaining Independence (1948-1988)

9. Our Leaders exhibition room

10. Presidents' Gifts exhibition room

11. Union of Myanmar Nationalities' Culture exhibition room

12. Art Galleries

13. Performing Arts exhibition room

14. Myanmar Art and Crafts exhibition room

15. ASEAN exhibition room

16. Children Discovery exhibition room

17. Special exhibition room

Although the National Museum (Nay Pyi Taw) has been under construction since 2010, it is not yet finished owing to the budget constraints. Thus, it has to be constructed and its exhibits are displayed portion by portion. For the first phase, 
Building (A) and Building (B) were opened in the 2014-2015 fiscal year. Building (C) and Building (D) will be finished in the 2015-2016 fiscal year as the second phase, and the last phase will be Building (E) in the 2016-2017 fiscal year.

\section{Exhibition at National Museum (Nay Pyi Taw)}

As the National Museum (Nay Pyi Taw) is a national-level museum, artifacts that represent the historical sequence of the successive period, arts and crafts cultural heritage, and our sovereignty are to be exhibited in the 17 exhibition rooms.

- For the first phase, the six rooms of Building (B) display the following six exhibition rooms: (1) B1- Primate and Fossils exhibition room; (2) B2- Prehistoric Period exhibition room; (3) B3- Art Gallery; (4) B4- Myanmar Performing Arts exhibition room; (5) B5- Protohistoric Period (second century BC to tenth century AD) exhibition room; and (6) B6- Historic Period of eleventh to fourteenth century AD exhibition room.

- In Building (C), there are four exhibition rooms: (1) C1- Historic Period of fourteenth to seventeenth century AD exhibition room; (2) C2, C3- Historic Period of eighteenth to nineteenth century AD exhibition room; (3) C4- Lion Throne exhibition room; (4) C5- Colonial Period (1885-1948) and the Period after gaining Independence (1948-1988).

- The following four exhibition rooms will be housed in Building (D): (1) D1Myanmar Art and Crafts exhibition room; (2) D2- ASEAN exhibition room; (3) D3- Children Discovery exhibition room; and (4) D4- Special exhibition room

- And Building (E) will showcase: (1) E1- Our Leaders exhibition room; (2) E2Presidents' Gifts exhibition room; (3) E3, E4- Union of Myanmar Nationalities' Culture exhibition room.

\subsection{Room B1 - Primate and Fossils Exhibition Room (Fig. 4)}

Primate fossils found in Myanmar will be displayed as the centerpiece. Scholars claim that the Pondaung primates are 40 million years old, which is 3 million years to 7 million years older than those found in Fayum, which are 33 million years old. It is pointed out that Myanmar is origin of human beings, which is something for the country to be proud of. In this exhibition room, the fossils of animals, feces, plants, and leaves are displayed. Besides, petrified wood of nearly $100 \mathrm{ft}$ long is displayed as the centerpiece 


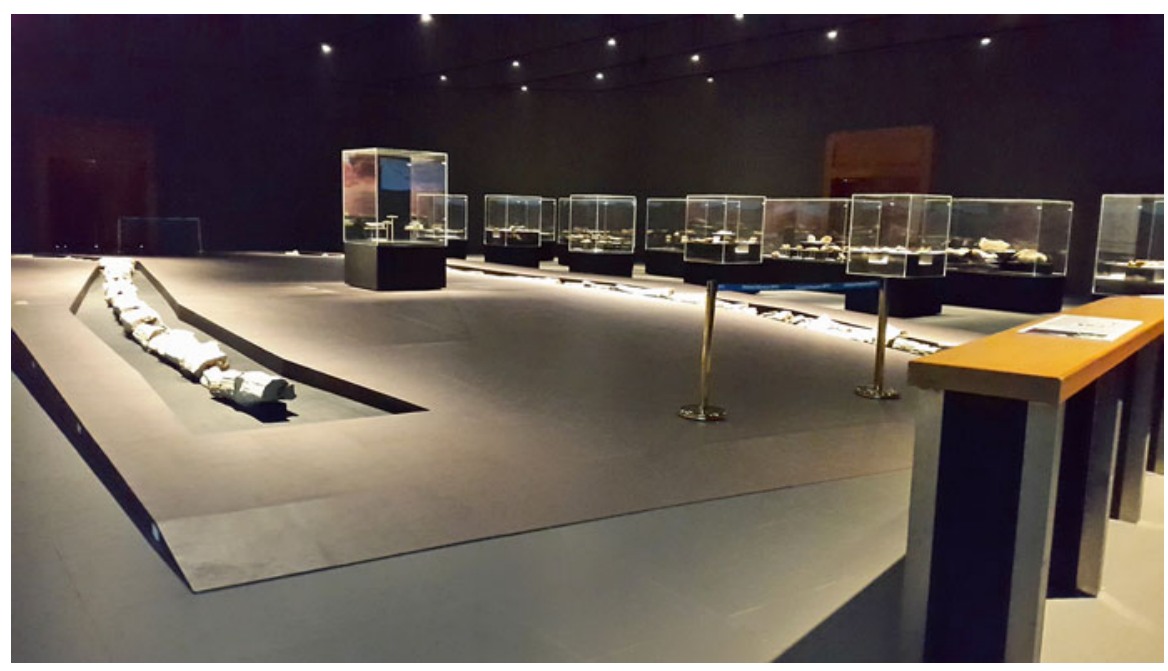

Fig. 4 Primate and fossils exhibition room

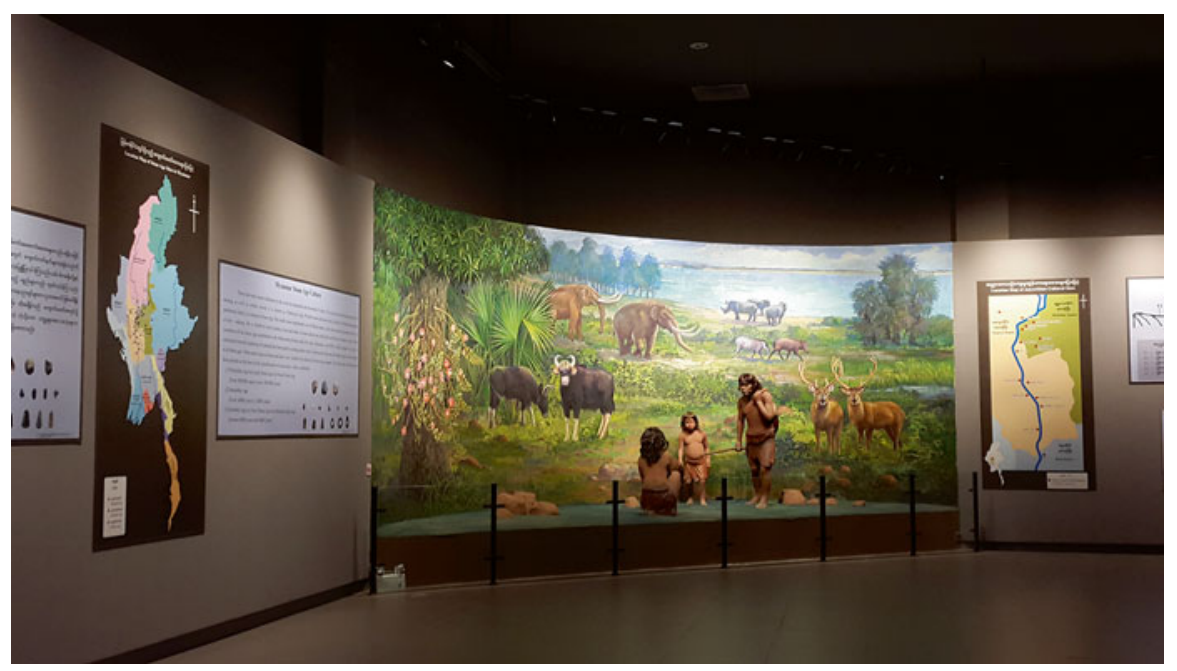

Fig. 5 Prehistoric period exhibition room

\subsection{Room B2 - Prehistoric Period exhibition room (Fig. 5)}

The prehistoric period comprises the Stone Age, Bronze Age, and Iron Age. Thus, in the Prehistoric Period exhibition room, an excavated Bronze Age site is created like a real one in the center of the room. A handrail is made to walk around the site. Stone implements $(5,000,000-4,000$ BP), bronze implements (4,000-3,000 BP), and the iron implements $(3,000 \mathrm{BP})$ found in Myanmar are also displayed in 


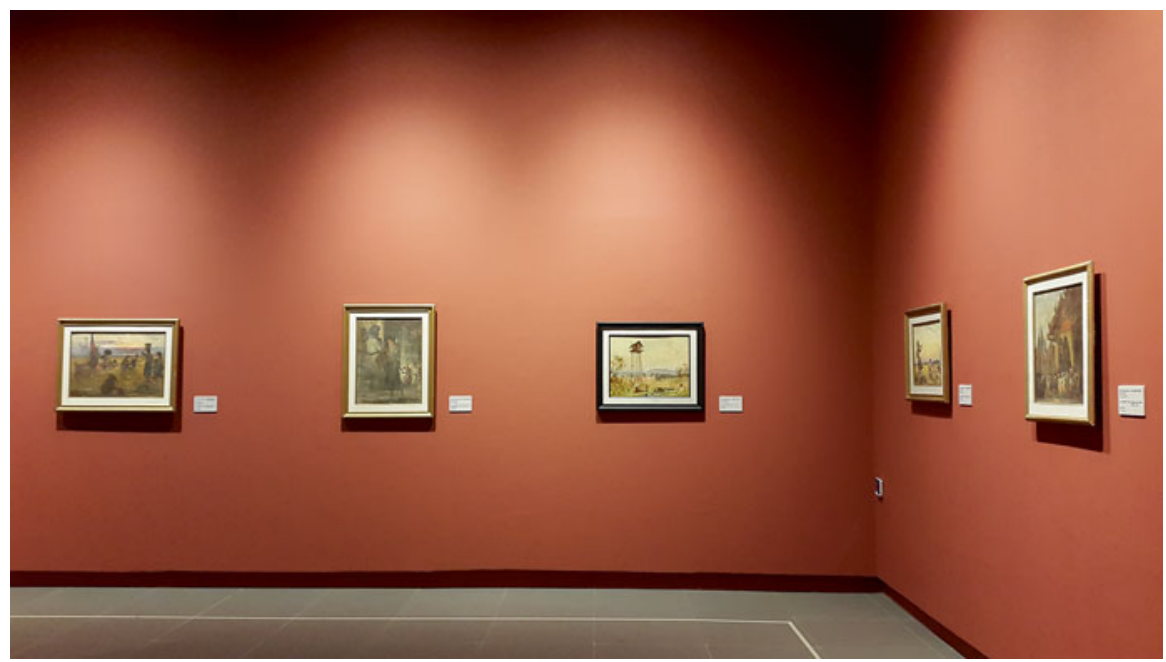

Fig. 6 Art gallery

the showcases. Besides, the Padalin cave in which there are mural paintings of the Neolithic Stone Age was made as a real-size model including models of Stone Age men drawing mural paintings, making fire, and making stone implements.

\subsection{Room B3-Art Gallery (Fig. 6)}

We show the history of Myanmar's paintings, mural paintings of the successive periods, Neolithic Stone Age mural paintings, mural paintings of the eleventh century $\mathrm{AD}$ to nineteenth century $\mathrm{AD}$, paper parchment paintings of the nineteenth century $\mathrm{AD}$, and contemporary art.

\subsection{Room B4- Performing Arts Exhibition Room (Fig. 7)}

Fine arts comprise an important factor for a country. Every country has its own fine arts and it is necessary to maintain them so that they do not deteriorate and they need to be showcased as precious items. The performing arts is an important component of the fine arts. The National Museum (Nay Pyi Taw) has thus planned to have a Myanmar Performing Arts exhibition room in Room B4. In this room, the history of Myanmar performing arts, Myanmar grand orchestra, Myanmar marionettes, and traditional instruments of nationalities are exhibited by using miniature models and figures. 


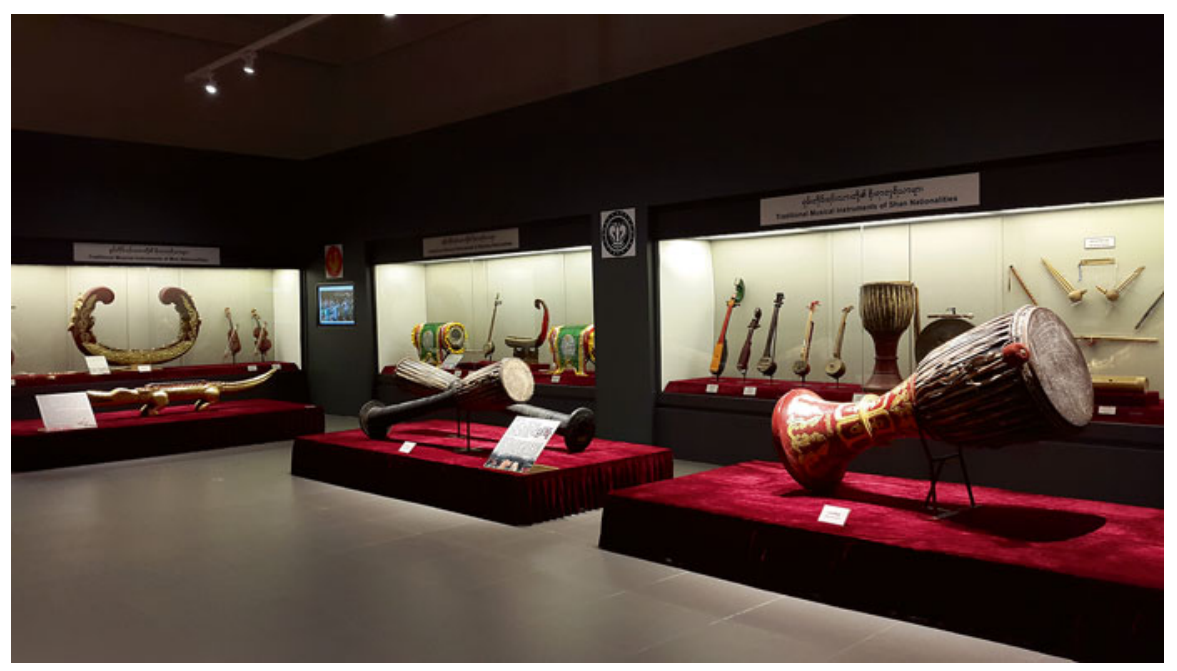

Fig. 7 Performing arts exhibition room

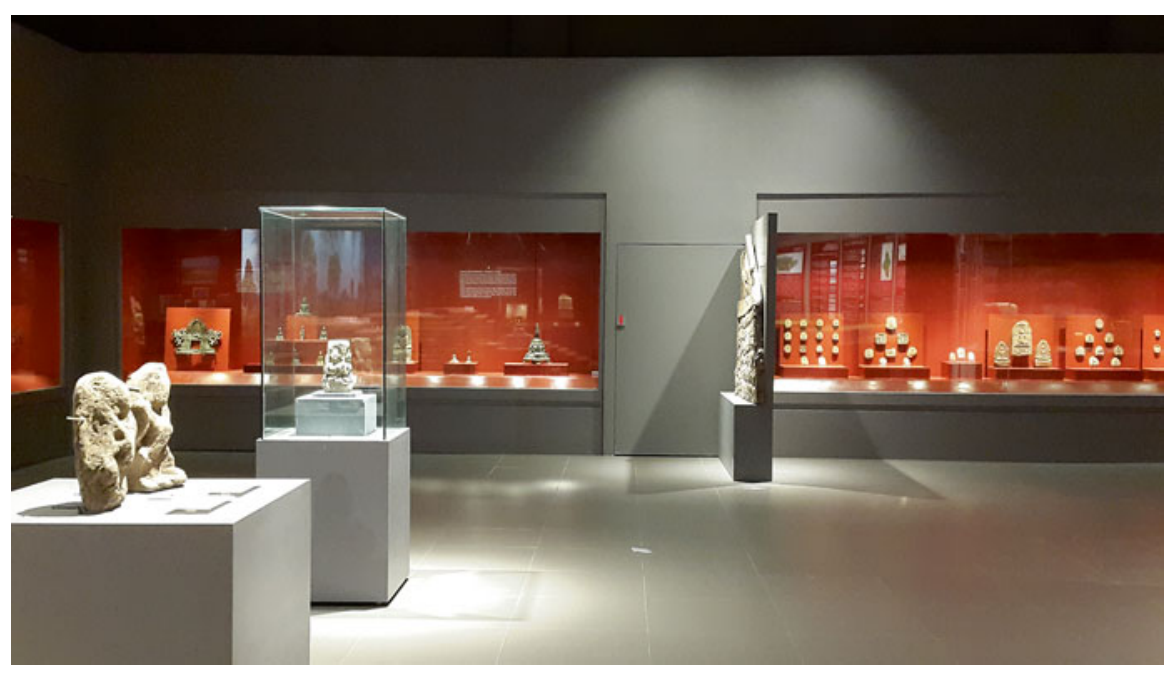

Fig. 8 Protohistoric period (second century BC to tenth century AD) exhibition room

\subsection{Room B5 - Protohistoric Period (Second Century BC to Tenth Century AD) Exhibition Room (Fig. 8)}

It consists of information about the Pyu civilization, which flourished between second century $\mathrm{BC}$ to tenth century $\mathrm{AD}$ (i.e., the protohistoric period). Here, miniature models of buildings, ornaments, Buddha statues, Brahmanism statues, burial urns, household utensils made of bronze and terracotta, and iron and coins of the Pyu period are displayed. 


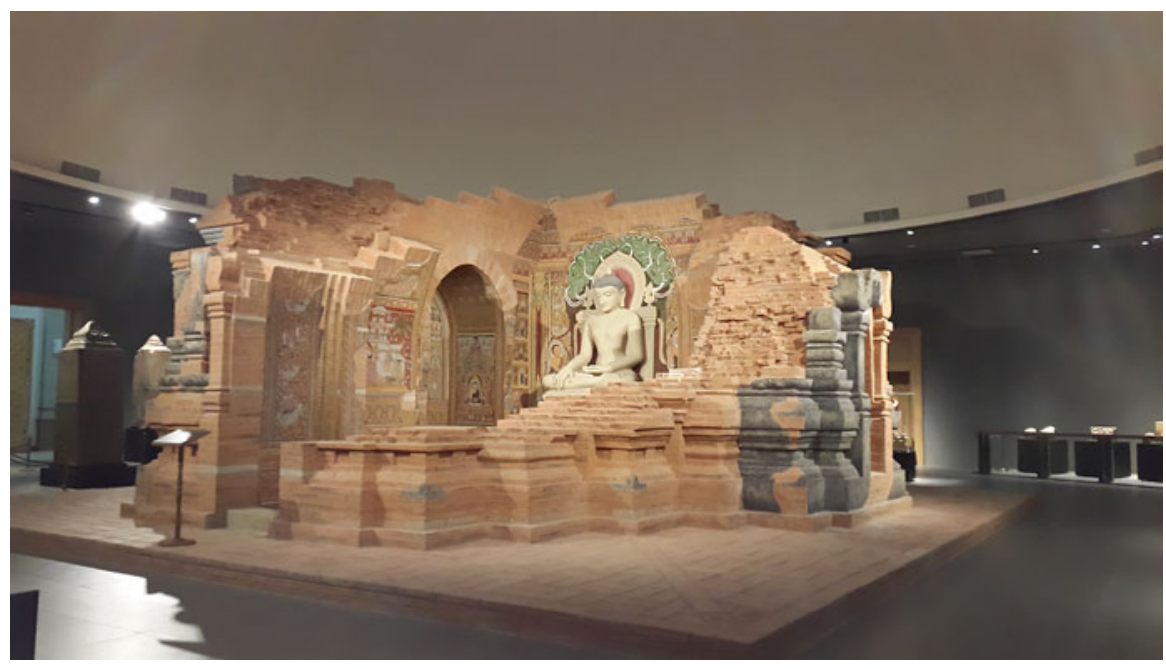

Fig. 9 Historic period of eleventh to fourteenth century AD exhibition room

\subsection{Room B6 - Historic Period of Eleventh to Fourteenth Century AD Exhibition Room (Fig. 9)}

Between the eleventh century AD and fourteenth century AD, civilization flourished vigorously in Bagan and it is famous as a Myanmar Cultural Heritage region situated in the central part of Myanmar. Artifacts of architecture, arts and crafts, literature, and religion of the Bagan period are displayed in this exhibition room. Besides, a section model of a Bagan-period temple has been constructed to display Bagan-period art and architecture.

\subsection{Room C1 - Historic Period of Fourteenth to Seventeenth Century AD Exhibition Room}

In Building (C), Room $\mathrm{C} 1$ is the Historic Period of the fourteenth to seventeenth century AD (Pinya, Innwa, Hamthawaddy, and Mrauk-U period) exhibition room. The culture of Myanmar's historic period commenced in the Bagan period (eleventh century AD) and successively developed into the Pinya, Innwa, Hamthawaddy, and Mrauk-U periods (fourteenth to seventeenth century AD). In this exhibition room, a miniature model of the palace of King Bayintnaung who was the founder of the Second Myanmar Kingdom in 1566 AD will be displayed. Rare antiquities such as ornaments, utensils, and other accessories of these periods will also be displayed. 


\subsection{Room C2, C3 - Historic Period of Eighteenth to Nineteenth Century AD Exhibition Room}

The Konbaung-Yadanapon Period exhibition room will display aspects of the Third Myanmar Kingdom founded by King AlaungPhaya. Moreover, a miniature model of the Yadanapon Palace built by the second-last king of Myanmar, King Mindon, will be exhibited. The Konbaung-Yadanapon Dynasty is the last dynasty of Myanmar (1752-1885 AD). Costumes, utensils, ornaments, and documents of these periods will be exhibited in this exhibition room.

\subsection{Room C4- Lion Throne Exhibition Room}

A replica of the Royal Lion Throne will be displayed altogether with royal regalia. Although it is a replica, the actual motive behind the display is to show Myanmar's sovereignty, which has existed for a long time. The real Lion Throne was used by Myanmar kings to sit on when the Royal Court was held in the palace.

\subsection{Room C5-Colonial Period (1885-1948) and the Period After Gaining Independence (1948-1988)}

Owing to annexation by the British government, Myanmar was a colonial country. In this exhibition room, evidence and documents of attempting to gain independence during the colonial period and documents of the period after gaining Independence (1948-1988) will be displayed.

\subsection{Room D1-Myanmar Art and Crafts Exhibition Room}

Myanmar possess ten traditional art and craft such as blacksmith, goldsmith, art of bronze casting, art of decorating with stucco, craft of a mason, art of carving, art of stone sculpture, craft of a turner, art of painting, art of making lacquer ware. In this exhibition room, not only the ten traditional art and crafts but also other Myanmar traditional crafts; making gold leaf, tapestry, weaving and glass mosaic will be displayed together with the explanation. 


\subsection{Room D2- ASEAN Exhibition Room}

As Myanmar is a member of the Association of South East Asia Nations (ASEAN), we need to praise about ASEAN and should educate and give more knowledge to the people about the emblem and objectives of ASEAN, National flowers, National flags and National land marks of the ASEAN member countries.

\subsection{Room D3- Children Discovery Exhibition Room}

The children are the most important in the building Nation because of the future generation. It is necessary to fulfill and promote their curiosity, knowledge and learning ability. Hence, National Museum (Nay Pyi Taw) creates a special children exhibition room including audio- visual about our Universe and our World, 3D painting of the evolution of flora and fauna, life size models of evolution of man, miniature models of the ancient settlement pattern, the costumes of our Nationalities and our neighboring countries, the explanation and scenery of 12 Myanmar traditional festivals, the Myanmar traditional weaving, excavation and recording methods for the antiquities. Moreover, the children can participate in "the build the city project" by using the puzzle blocks.

\subsection{Room D4- Special Exhibition Room}

This exhibition room is actually a temporary exhibition room and can exhibit according to the title or subject or objects quarterly or yearly.

\subsection{Room E1- Our Leaders Exhibition Room}

In this exhibition room, our National Leaders such as General Aung San, Presidents and Prime Ministers of the successive period will be displayed as the historical evidences.

\subsection{Room E2- Presidents' Gifts Exhibition Room}

When the Presidents of the Republic of the Union of Myanmar visit to abroad or the foreign diplomats visit to Myanmar, the gifts are always presented as the good well presents. Those presents are precious and artistic and people can have the great chance to see them and can study about the other foreign countries' culture. 


\subsection{Room E3, E4- Union of Myanmar Nationalities' Culture Exhibition Room}

As the Union of the Republic of Myanmar has various nationalities, they live intimately in our country. Hence, the National Museum (Nay Pyi Taw) has a detailed plan for display on nationalities in rooms E 3 and E4. The display will comprise their lifestyle, tradition, culture, religion, literature, and habits. Thus, traditional instruments, implements, ornaments, and clothes of the nationalities will be showcased. Moreover, their traditions and festivals will be displayed by using miniature models and figures.

According to the exhibition rooms, there are a great variety of display objects made of different materials such as gold, silver, bronze, iron, stone, terracotta, glaze, porcelain, animal bone, wood, bamboo, cane, textile, paper, and fiberglass.

There are altogether 12,975 display objects collected as follows:

\begin{tabular}{l|r}
\hline Stone objects & 6,128 \\
\hline Bronze objects & 2,457 \\
\hline Iron objects & 190 \\
\hline Gold objects & 43 \\
\hline Silver objects & 706 \\
\hline Terracotta objects & 1,470 \\
\hline Glazed objects & 145 \\
\hline Porcelain objects & 38 \\
\hline Glass objects & 14 \\
\hline Machinery & 110 \\
\hline Lead objects & 29 \\
\hline Animal objects & 43 \\
\hline Wooden objects & 420 \\
\hline Lacquer, bamboo, cane objects & 245 \\
\hline Textiles & 526 \\
\hline Paper objects & 175 \\
\hline Paintings & 369 \\
\hline Seals & 135 \\
\hline Replicas & 52 \\
\hline Other & 80 \\
\hline Total & 12,945
\end{tabular}

The National Museum (Nay Pyi Taw) has been collecting display objects although it has not yet opened totally (Fig. 10). 

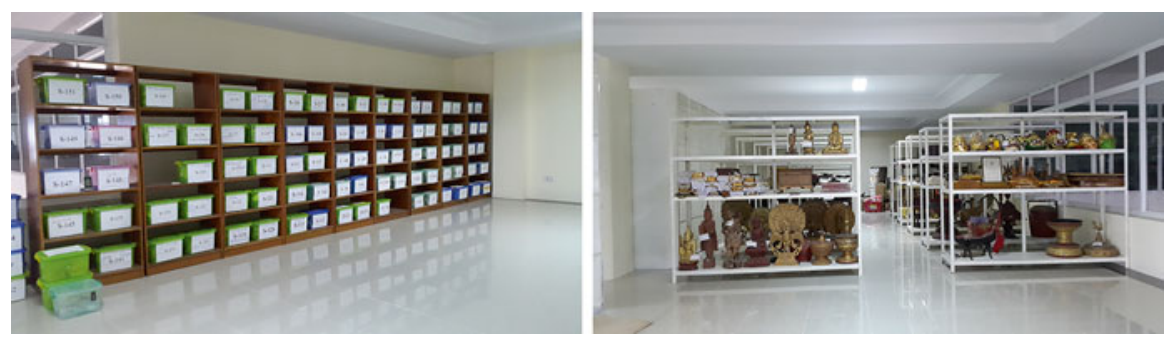

Fig. 10 Storerooms at the National Museum (Nay Pyi Taw)

\section{Documentation at National Museum (Nay Pyi Taw)}

When the display objects arrive at the Museum, they have to be entered in the "Entry record" including identification such as gift, purchase, loan, or transfer with the signature, name, and address of the depositor. And then it is necessary to give each object an accession number (Crafts Museum India 2004; ICCROM). At present, a tripartite or trinomial system is being used. In this system, the first number is usually the year the accession was made. The second number is the lot number that is designated by type of material. The third number is the object number accessioned in a particular lot. For example, if a bronze object is accessioned in 2013 and its serial number in lot is 100 , the accession number is $2013,1,100$.

The lot numbers are given together with the materials as follows:

1. Stone objects

2. Bronze objects

3. Iron objects

4. Gold objects

5. Silver objects

6. Terracotta objects

7. Glazed objects

8. Porcelain objects

9. Glass objects

10. Machinery

11. Lead objects

12. Animal objects

13. Wooden objects

14. Lacquer, bamboo, and cane objects

15. Textiles

16. Paper objects

17. Paintings

18. Seals

19. Replicas

20. Other 
After that, proportions and weight are measured, photographs are taken, and then index cards are filled in and attached to the objects. Entries are made in the registration record and the museum objects database. When a display object is positioned, a location and movement record is necessary. Whenever the object is moved, this is recorded and so it is easy to find the object. When any object is borrowed or lent, a "Loan record (incoming)" or "Loan record (outgoing)" is filled in. Although the National Museum (Nay Pyi Taw) has not yet opened totally, the collected display objects have been lent to foreign museums such as the Quanxi Museum for Nationalities, China in 2011, the Metropolitan Museum of Art in New York, United States of America, in 2014, and the Asia Society in New York, United States of America, in 2015.

\section{Conservation at National Museum (Nay Pyi Taw)}

The most important step in the conservation process is to document the existing condition of the object. Documentation is done for every object that has been brought into the conservation laboratory prior to any treatment. In this document, the physical condition such as any cracks, disfigurement to the object, any sign of damage or wear, addition and losses, previous restoration, color change, insect damage, and bio deterioration are mentioned. And then the method of treatment is documented to allow the conservators to monitor and assess the effectiveness of the treatment in the future. Moreover, reconstruction and restoration works are also completely documented and the administrative details are recorded. When the treatment is completed, the condition of the object is documented again for comparison with its pretreatment condition. The National Museum (Nay Pyi Taw) is using both textual documentation and visual documentation. For textual documentation, the checklist style of documentation is used and digital photos are used for visual documentation. And then both are installed as a computer database (Moore 2000).

A major objective of all conservation treatments is to increase the chemical stability of the object being treated. Cleaning often forms an important part of the stabilizing process. This is because dirt on an object can be a potent source of deterioration (as, for example, when chloride salts set up corrosion reactions on bronze, or moulds grow on organic materials like paper or textiles). At other times, cleaning may be a necessary preliminary to a further treatment (Conservation Unit Museums and Galleries Commission 1992). Therefore, cleaning the dirt is the main conservation work in the National Museum (Nay Pyi Taw) (The National Museum (Nay Pyi Taw) 2012).

"Dirt" can be classified into two types:

1. Foreign matter that is not part of the original object

(Examples: soot, grease, stains, adhesives, and fillings from previous treatment)

2. Products of alteration of the original materials 


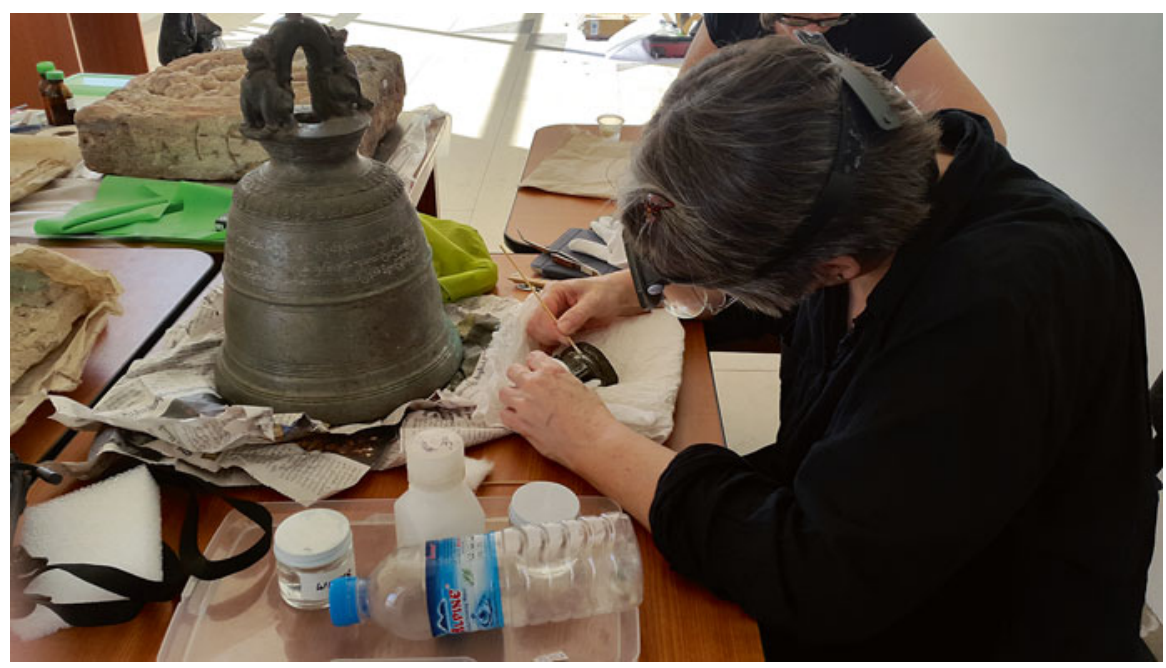

Fig. 11 Conservation of bronze objects

(Examples: metal corrosion products and decayed timber or stone)

Dust (foreign matter) is commonly an amazing mixture of fragments of human skin, textile fibers, carbon particles (soot), and grease from unburned hydrocarbon fuels, from cooking and from the skin of people and animals. There are many salts in dust, for example, sodium chloride and sharp gritty silica crystals are often present. In this chemical mixture are the spores of countless moulds and fungi and micro-organisms that are equally likely to attack objects made of organic material. Much of this dirt is hygroscopic (water-attracting) and this tendency can encourage the growth of moulds and increase the corrosiveness of salts. So even dust is damaging although perhaps only slowly. If the dust is a product of alteration of part of an object, some of the object itself will be taken away when removing the dust. For instant, when the tarnish on a silver object is cleaned away, not only the sulfur atoms that are foreign matter but also some silver atoms originally positioned by the silversmith.

Conservation has to be done according to the type of object. Object types can be classified as (1) metal objects, (2) organic objects, and (3) inorganic objects.

1. Metal objects include bronze, gold, silver, and lead.

- For bronze objects, both physical and chemical cleaning methods are used. In the physical method, corrosion products are removed by using simple mechanical tools such as a pin, scalpel, chisel, hammer, and motor drive vibrator. And then the final rub is done by using fine emery paper to bring out the inner patina. The chemical cleaning method is where the bronze object is immersed in $5 \%$ citric acid $\left(\mathrm{T}-60-80^{\circ} \mathrm{C}\right)$ and washed with distilled water and then dried (Fig. 11). 
- Gold objects are soaked in $2 \%$ caustic soda solution to remove the organic remains. Normally, corrosion does not take place on gold objects and they can be cleaned by using distilled water.

- Silver objects are cleaned by immersing in $10 \%$ formic acid for an hour and washed with distilled water and dried.

- The incrustation on lead objects can be cleaned by using $10 \%$ acetic acid by means of a brush.

- For iron objects, rust can be removed by boiling repeatedly in $10 \%$ caustic soda for three weeks. Lumps of lime incrustation can be removed by dilute nitric acid before treatment with caustic soda.

2. Organic objects include wood, palm leaf, paper, bamboo, lacquer, textile, bone and ivory, and feather and leather.

- Wooden objects are easily affected by insects. Insect-attacked wooden objects should be fumigated in the laboratory but this cannot be done in the National Museum (Nay Pyi Taw) because there is no fumigation chamber. Thus, cleaning can be only done by using rectified spirit.

- For palm leaf manuscripts, the dust on the leaves is cleaned with a brush, the leaves are cleaned with rectified spirit, and 5\% lemongrass oil in rectified spirit is then applied.

- Paper objects can be decayed by moisture, dust, insects, faulty storage, etc. Paper objects should be kept at $60 \%$ RH. If it is not, paper will absorb the moisture and acidity in the paper will form acid and then the paper will decay. In the storage room of the National Museum (Nay Pyi Taw), the relative humidity is adjusted to about $60 \%$.

- Bone and ivory are cleaned by using rectified spirit.

- Feather and leather are kept under a condition of $60 \%$ RH and a temperature is $20^{\circ}$.

3. Inorganic objects such as clay objects and stone objects can be cleaned with a brush first. Baked clay objects can be soaked in water repeatedly to clean them. Stains of oil, wax, or paint on stone objects can be cleaned by acetone and a $5 \%$ solution of ammonium hydroxide is used to remove the algae (Fig. 12).

The collected display objects in the National Museum (Nay Pyi Taw) are just cleaned and consolidated; coating is rarely done so as not harm the aesthetic beauty of the object.

\section{Conclusion}

In fact, Myanmar has a long history of culture and a great many cultural heritages both tangible and intangible. The National Museum (Nay Pyi Taw) is trying to reflect this precious Myanmar cultural heritage and planning to collect and display the objects in the best and most interesting museum in the world. Hence, it is also 


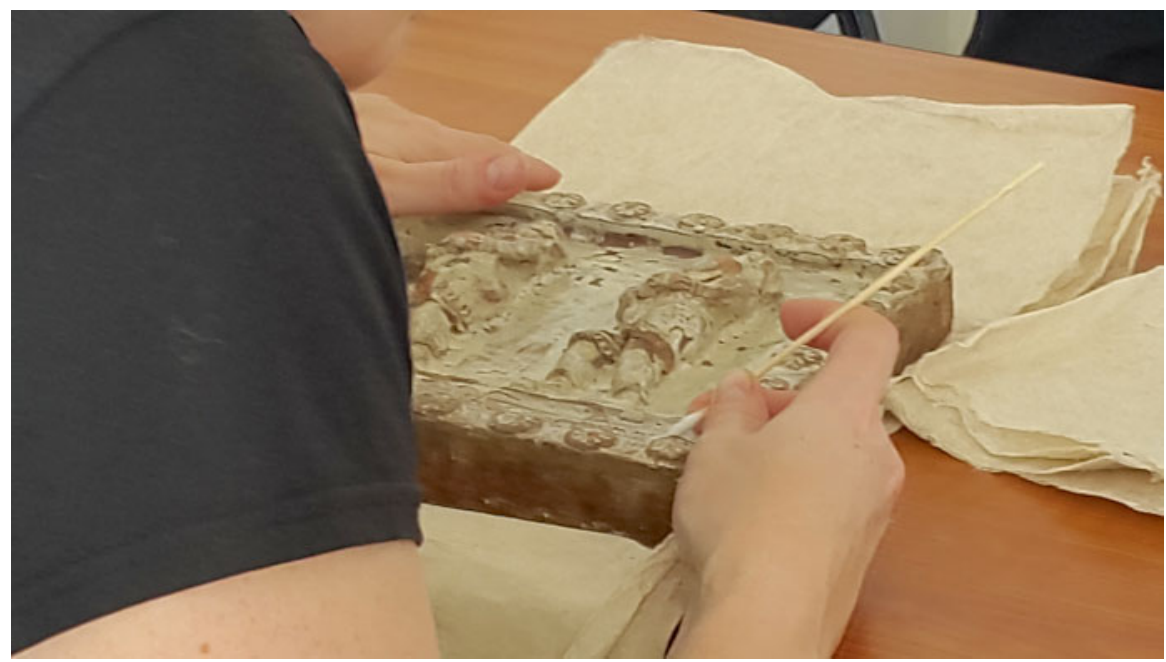

Fig. 12 Conservation of clay objects

important not only to do conservation and documentation works but also to exhibit by using modern techniques. The National Museum (Nay Pyi Taw) is still under construction and two buildings including six exhibition rooms were opened on 15 July 2015 as the first phase and the remaining buildings will be opened phase by phase in the coming years. For the national-level exhibition rooms, display objects are being collected. Some of these are excavated from ancient sites and some are collected by donation, exchange, and given as awards. Each and every display object arriving at the National Museum (Nay Pyi Taw) is systematically documented. These museum display objects need to be preserved and conserved in a conservation laboratory with the full equipment. However, the display objects are being conserved by using simple chemicals and ordinary equipment. Therefore, the National Museum (Nay Pyi Taw) has been undertaking the documentation, conservation, and exhibition process voluntarily.

Notes This paper was first presented in February 2015 at the international symposium "New Horizons for Asian Museums and Museology." As the National Museum (Nay Pyi Taw) was opened in July 2015 (the first phase), the contents of the paper has been updated.

Present affiliation of the author: Cultural Museum (Taunggyi), Myanmar

Open Access This chapter is distributed under the terms of the Creative Commons AttributionNonCommercial 4.0 International License (http://creativecommons.org/licenses/by-nc/4.0/), which permits any noncommercial use, duplication, adaptation, distribution and reproduction in any medium or format, as long as you give appropriate credit to the original author(s) and the source, provide a link to the Creative Commons license and indicate if changes were made.

The images or other third party material in this chapter are included in the work's Creative Commons license, unless indicated otherwise in the credit line; if such material is not included in the work's Creative Commons license and the respective action is not permitted by statutory regulation, users will need to obtain permission from the license holder to duplicate, adapt or reproduce the material. 


\section{References}

Conservation Unit Museums and Galleries Commission. 1992. The science for conservators series: Volume-2 cleaning. London/New York: Taylor \& Francis.

Crafts Museum, India. 2004. Accession register. New Delhi: Naveen Printers.

ICCROM. Documentation of museum collection, UNESCO, ICCROM, and EPA. http://www.epaprema-net/documents/ressources/manual.htm. Accessed 22 Apr 2011.

Moore, Michelle. 2000. Conservation documentation and the implications of digitization. UK: Institute of Archaeology.

The National Museum (Naypyitaw). 2012. Manual for conservators. (Internal communication). 